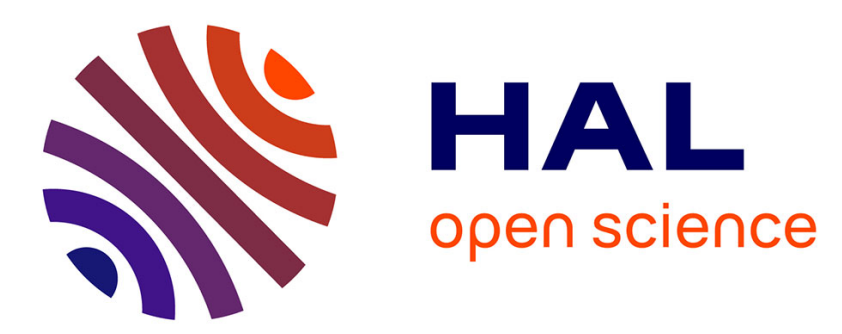

\title{
Modeling of Conjugate Heat Transfer in a Kerosene/Air Spray Flame used for Aeronautical Fire Resistance Tests
}

L. Boulet, Pierre Benard, G. Lartigue, Vincent Moureau, S. Didorally, N. Chauvet, F. Duchaine

\section{- To cite this version:}

L. Boulet, Pierre Benard, G. Lartigue, Vincent Moureau, S. Didorally, et al.. Modeling of Conjugate Heat Transfer in a Kerosene/Air Spray Flame used for Aeronautical Fire Resistance Tests. Flow, Turbulence and Combustion, 2018, 101 (2), pp.579-602. 10.1007/s10494-018-9965-8 . hal-02107316

\section{HAL Id: hal-02107316 https://hal.science/hal-02107316}

Submitted on 11 Jan 2021

HAL is a multi-disciplinary open access archive for the deposit and dissemination of scientific research documents, whether they are published or not. The documents may come from teaching and research institutions in France or abroad, or from public or private research centers.
L'archive ouverte pluridisciplinaire HAL, est destinée au dépôt et à la diffusion de documents scientifiques de niveau recherche, publiés ou non, émanant des établissements d'enseignement et de recherche français ou étrangers, des laboratoires publics ou privés. 


\title{
Modeling of conjugate heat transfer in a kerosene/air spray flame used for aeronautical fire resistance tests
}

\author{
L. Boulet*† P. Bénard ${ }^{\star} \quad$ G. Lartigue ¿ $^{\star} \quad$ V. Moureau* \\ S. Didorally ${ }^{\dagger} \quad$ N. Chauvet $^{\ddagger} \quad$ F. Duchaine ${ }^{\S}$
}

September, 2017

\begin{abstract}
Airworthiness standards require a fire resistance demonstration for aircraft or helicopter engines to obtain a type certificate. This demonstration relies on tests performed with prototype engine parts in the late stages of the development. In hardest tests, a kerosene standardized flame with imposed burnt gas temperature and heat flux is placed next to the engine casing during a given time. The aim of this work is to provide a better characterization of a kerosene/air certification burner in order to reach a better understanding of the thermal environment during fire tests.

To this purpose, Large-Eddy Simulation (LES) of the certification burner is carried out. Spray combustion, forced convection on walls and conduction in the solid parts of the burner are coupled to achieve a detailed description of heat transfer. In a first place, physical aspects involved inside the burner in an adiabatic case are described. Then, differences that exist with a conjugate convective and conductive heat transfer case are analyzed. To a larger extent, the aim is to have a better characterization of the flow impinging the casing and to progress on fire test modeling so as to minimize the risks of test failure.
\end{abstract}

\section{Introduction}

As part of the development of new engines, aeronautical companies need to follow the European Aviation Safety Agency regulations. Its technical specifications impose special care against fire risk (circular CS-E, paragraph 130 [1]). It stipulates that working equipments, potentially subject to flames, should be fireproof or fire resistant. The acceptance criterion of these tests mainly resides in the fact that fire should not be maintained and that there is no oil leak with quantities that may involve hazardous effects, like harmful smokes. Engine housing fire tests are certified procedures according to norm ISO 2685 [2]. The USA also own their norm (AC 20-135 [3]), controlled by the FAA (Federal Aviation Administration). The principle of the ISO European test is to submit the equipment to be certified to a standardized flame during a given time specified by certification rules. The standardized flame features are a temperature of $1100 \pm 80{ }^{\circ} \mathrm{C}$ (i.e. $1373 \pm 80 \mathrm{~K}$ ) and a density flux absorbed by a standardized calorimeter of $116 \pm 10 \mathrm{~kW} / \mathrm{m}^{2}$.

There is a consequent literature about fire behaviors of composite material in the aircraft fire certification field. For example, Tranchard [6] evaluated and examined the fire behavior of carbon fibre epoxy composite. However, from experimental or simulation context, there are few numerical calculations to our knowledge. Recently, Kao [7] experimentally studied the sensitivity of the burner performance varying fuel/air ratio, as well as the influence of the turbulator (to stabilize the flame, see Section 3.1) and the thermocouple size used for flame calibration. The study, performed

\footnotetext{
*CORIA, CNRS UMR 6614, Normandie Université, INSA and University of Rouen, 76801, Saint-Étienne-duRouvray, France

E-mail: vincent.moureau@coria.fr, ghislain.lartigue@coria.fr

†SAFRAN Aircraft Engines Villaroche, Rond Point René Ravaud - Réau 77550 Moissy-Cramayel, France

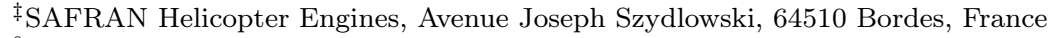

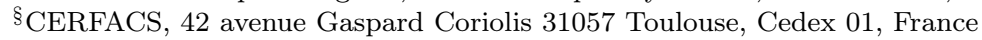




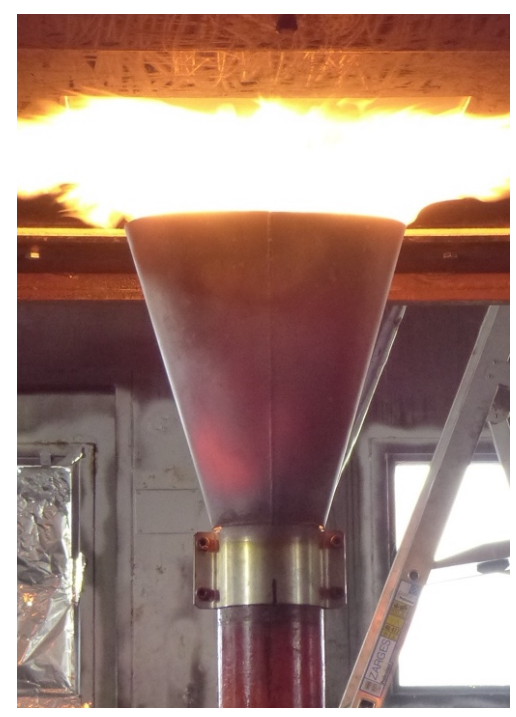

Figure 1: Picture of a running Park DPL 3400 kerosene burner

by conducting fire tests on aluminum samples, shows the inadequacies in the current calibration standards. Interest about modeling fire tests goes back to the 2000s, when Neely [8] simulated the propane/air burner with a Finite Element (FE) approach and was capable to reproduce the temperature field of an aircraft ring under flame attack. Later, thanks to Computational Fluid Dynamics (CFD) with a RANS approach for the fluid phase and a FE model for the solid, Dimitris [9] investigated the burn-through response of composite structures with the gas burner. Even if the numerical results slightly vary from the experimental ones due to strong assumptions, numerical results follow the trend of the experience. Concerning the liquid kerosene burner, a first RANS study [10] compares the thermal behavior of a composite material during a fire stress. In this study, the torch modeling is limited to the cone without fluid/solid interactions and the flame is reduced to a unique hot gas without detailed chemistry.

In the present paper, a high-fidelity study of the flow inside the torch is conducted in order to understand the flame dynamics and have a more precise characterization of the heat flux on the engine casing. Ultimately, these simulations will help in increasing the confidence level in the casing design before the certification tests. The Large-Eddy Simulation (LES) approach, which resolves the large scale of the flow and models the impact of the small scales onto the large ones, is chosen as it gives access to the flame dynamics. It is also more accurate than RANS methods for this type of internal flow with spray combustion. Strong interactions that exist between the fluid phase and the solid, called Conjugate Heat Transfer (CHT), are investigated. Radiation of burnt gases as well as radiation of the equipment are not taken into account in this first modeling step. But the modeling of CHT is still a challenge due to the large range of multi-physic characteristic times and long computation time.

The remainder of this paper is structured as follows. First, an introduction of the numerical tools for the simulations and the coupling strategy between fluid and solid phases is given Section 2. The fire-test computational set-up, discussed in Section 3, is followed by an analysis of the flame topology in an adiabatic case. Then, comparison of this case with a coupled heat transfer simulation of the burner is performed in Section 4. Finally, conclusions and outlooks are given in Section 5.

\section{Numerical methodology}

Before detailing the coupling tools, the reactive flow solver and the solid solver are described. The reactive flow solver section introduces the approach of both Eulerian gas phase and Lagrangian liquid phase after a few words about chemistry aspects. 


\subsection{Reactive flow solver}

Large-Eddy Simulations are carried out thanks to the finite-volume solver YALES2 [11]. This LowMach number code is able to handle complex unstructured meshes on massively parallel systems and to manage very large computational grids. To solve the unsteady filtered variable-density Navier-Stokes equations [12], it uses the projection method of Chorin [13] modified by Kim \& Moin [14], based on the Helmholtz-Hodge decomposition. It enables to remove the constraints due to acoustics at low-Mach number. The integration of the equations is made with a 4th-order central scheme in space and a TFV4A 4th-order scheme in time, which combines a 4th-order Runge-Kutta scheme with a Lax-Wendroff-like scheme also of the 4th-order [15].

\subsubsection{Chemistry for kerosene surrogate}

As indicated in the previous section, the fuel of interest is kerosene. Actually, Kerosene is a mixture of different hydro-carbons of different weights with some additives. It owns many thousands species and does not have an accurate composition but a chromatography $[16,17]$ can reveal that specific chemical classes are more important than others. In particular, Jet A-1 holds three main classes of pure compounds: paraffinic, naphthenic and poly-cyclic aromatic hydrocarbons [18]. In terms of numerical simulation, this big amount of species would involve heavy kinetic mechanisms. This complexity of mixing requires to simplify the number of species via a model, named surrogate.

Although kerosene surrogates are quite new, the literature lists a vast number of them due to the wide range of applications, from the premixed laminar flame [19, 20] to the Jet Stirred Reactor [21, 22 ], or because of the possibility to respect either physical or chemical properties, or both of them [23, 24]. Between the first surrogate of Schulz [25], that contains 12 compounds, and the light surrogate of Delfau [26], that owns only n-decane, Cathonnet [27] and Dagaut [28] have found a compromise with three compounds. This last surrogate is the basis of a lot of kinetic schemes, allowing to describe the kinetics of kerosene/air combustion, especially the Luche scheme [29]. This skeletal scheme is mainly used in a semi-industrial context thanks to its reasonable number of species and reactions (92 and 694, respectively) and its ability to reproduce combustion properties correctly such as laminar flame speed or adiabatic temperature on a wide range of equivalence ratios, pressure and temperature. Because the future simulations will be carried out on a mesh with thousands of cells in a complex geometry, a simpler scheme need to be used. So, this study will employ a semi-global two-step reaction scheme with six species derived from the Luche scheme, the BFER scheme [30]. This scheme was validated in a large range of temperature and air-fuel ratio at atmospheric pressure. Furthermore, it allows the fastest computation times compared to the others, so that the simulation is not limited by the chemistry, and to reach a compromise between scheme complexity and CPU time.

Moreover, this direct Arrhenius chemical kinetics approach is favored due to complex phenomena involved inside the burner, like composition inhomogeneities, combustion regimes, buoyancy effects or energy losses and exchanges with the walls. Details about computational implementation in YALES2 are available in Bénard [31], that applied this complex chemistry model to a methane/air mixture in a meso-combustor.

\subsubsection{Gas phase}

In an LES context, the Navier-Stokes transport equations undergo a spatial filtering operation so that the large scales of the turbulent flow can be solved provided that the small scales are modeled. This method allows to dramatically reduce the CPU time compared to Direct Numerical Simulation, making the LES affordable in an industrial context. In the following, ${ }^{-}$and ${ }^{\sim}$ symbols will denote the unweighted and Favre filtering operators, respectively. The set of filtered governing equations (continuity, momentum, energy and species transport) is written:

$$
\begin{gathered}
\frac{\partial \bar{\rho}}{\partial t}+\frac{\partial \bar{\rho} \widetilde{u}_{i}}{\partial x_{i}}=\sum_{k=1}^{n_{s p}} \Theta_{M, k} \\
\frac{\partial \bar{\rho} \widetilde{u}_{j}}{\partial t}+\frac{\partial \bar{\rho} \widetilde{u}_{i} \widetilde{u}_{j}}{\partial x_{i}}=-\frac{\partial \bar{P}}{\partial x_{j}}+\frac{\partial\left(\tau_{i j}^{l a m}+\tau_{i j}^{s g s}\right)}{\partial x_{i}}+\Theta_{D, j},
\end{gathered}
$$




$$
\frac{\partial \bar{\rho} \widetilde{h}_{s}}{\partial t}+\frac{\partial \bar{\rho} \widetilde{u}_{i} \widetilde{h}_{s}}{\partial x_{i}}=\frac{D \overline{P_{0}}}{D t}+\frac{\partial}{\partial x_{i}}\left(\lambda \frac{\partial \widetilde{T}}{\partial x_{i}}-\frac{\mu_{t}}{P r_{t}} \frac{\partial \widetilde{h}_{s}}{\partial x_{i}}\right)+\frac{\partial}{\partial x_{i}}\left(-\bar{\rho} \sum_{k=1}^{n} D_{k} \frac{\partial \widetilde{Y}_{k}}{\partial x_{i}} \widetilde{h}_{s, k}\right)+\overline{\dot{\omega}}_{T}+\frac{\partial q_{i}}{\partial x_{i}}+\Theta_{h_{s}}
$$

$$
\frac{\partial \bar{\rho} \widetilde{Y}_{k}}{\partial t}+\frac{\partial \bar{\rho} \widetilde{u}_{i} \widetilde{Y}_{k}}{\partial x_{i}}=\frac{\partial}{\partial x_{i}}\left(\frac{\bar{\rho} \mu_{t}}{S c_{t}} \frac{\partial \widetilde{Y}_{k}}{\partial x_{i}}\right)+\frac{\partial}{\partial x_{i}}\left(\bar{\rho} D_{k} \frac{\partial \widetilde{Y}_{k}}{\partial x_{i}}\right)+\overline{\dot{\omega}}_{k}+\Theta_{M, k}
$$

In Eqs. 1-4, the density, the dynamic viscosity, the molecular diffusion coefficient of the species $k$, the thermal conduction coefficient, the velocity, the dynamic pressure, the temperature and the mass fraction of the species $k$ are denoted by $\rho, \mu, D_{k}, \lambda, u, P, T$ and $Y_{k}$, respectively. The energy conservation is written here with the sensible enthalpy $h_{s}=\int_{T_{0}}^{T} C_{p} d T$, with $C_{p}$ the heat capacity at constant pressure. To close the problem, the fluid is supposed to follow the ideal gas law for filtered quantities: $\overline{P_{0}}=\bar{\rho} \widetilde{r} \widetilde{T}$, where $P_{0}$ is the thermodynamic pressure and $r$ is the mixture gas constant.

In a conventional manner, the filtered laminar stress tensor is $\tau_{i j}^{l a m}=2 \mu \widetilde{S}_{i j}^{d}$, with $\tilde{S}_{i j}^{d}$ the deviatoric part of the resolved strain rate tensor. The unresolved Sub-Grid Scale stress tensor is modeled using the Boussinesq assumption [32] as $\tau_{i j}^{s g s}=2 \mu_{t} \widetilde{S}_{i j}^{d}$, with $\mu_{t}$ the sub-grid turbulent viscosity given by the turbulence model. The dynamic Smagorinsky, developed first by Germano [33], has been chosen because of its wide range of applications and the fact that the Smagorinsky constant is locally computed from the knowledge of the velocity field.

In the case of a BFER kerosene chemistry, the scheme imposes a constant species Schmidt number $S c_{k}=0.739$ and a constant Prandtl number $\operatorname{Pr}=0.739$ for the mixture so as to have a unity Lewis number. A power law for the mixture viscosity has also to be used, and only depends on the temperature.

Combustion modeling relies on a Thickened Flame Model (TFLES) [34], in which the flame front is thickened to resolve it on grid mesh whose characteristic size is greater than the flame thickness. In order to limit its usage to the flame only, this model is applied dynamically via a flame sensor [35], based on the combination of $\mathrm{CO}_{2}, \mathrm{CO}$ and $\mathrm{H}_{2} \mathrm{O}$ source terms, which marks the reactive zones. This dynamic version of the TFLES model is mandatory to avoid an artificial increase of the thermal conductivity everywhere in the flow domain. The efficiency function involved in the TFLES model is given by the original non-saturated Charlette model [36]. There is no correction of evaporation and drag of this model but the diffusion coefficients in the evaporation model are determined without taking into account the thickening factor. Else it would lead to unphysical evaporation time.

The heat release due to combustion involves the enthalpy of formation $\Delta h_{f, k}^{0}$ and the reaction rate $\overline{\dot{\omega}}_{k}$ of the species $k: \overline{\dot{\omega}}_{T}=-\sum_{k=1}^{n_{s p}} \Delta h_{f, k}^{0} \overline{\dot{\omega}}_{k}$, with $n_{s p}$ the total number of species.

$\frac{\partial q_{i}}{\partial x_{i}}$ is the divergence of the radiative heat flux $q_{i}$ and corresponds to the radiation term, that is neglected in the present study.

$\Theta_{M, k}, \Theta_{D}$ and $\Theta_{h_{s}}$ are source terms that represent the retro-action of the liquid droplets on the fluid phase. Details can be found in Guedot [37].

\subsubsection{Liquid phase}

The spray transport model uses a point-particle Lagrangian approach, where spherical droplets are all represented and on which Newtonian mechanics can be applied. The kinetic equation for a given droplet is:

$$
\frac{\mathrm{d} \mathbf{x}_{p}}{\mathrm{~d} t}=\mathbf{u}_{p}
$$

where $\mathbf{x}_{p}$ is the position of the droplet and $\mathbf{u}_{p}$ its velocity.

The conservation of momentum is given by Newton's second law:

$$
\frac{\mathrm{d}}{\mathrm{d} t}\left(m_{p} \mathbf{u}_{p}\right)=\mathbf{F}_{p}^{G}+\mathbf{F}_{p}^{A}+\mathbf{F}_{p}^{I}
$$

where $m_{p}$ is the mass of the droplet, $\mathbf{F}_{p}^{G}$ is the buoyancy force, $\mathbf{F}_{p}^{A}$ is the aerodynamics force and $\mathbf{F}_{p}^{I}$ is the wall-droplet or droplet-droplet contact force. The buoyancy force is written as: 


$$
\mathbf{F}_{p}^{G}=\left(\rho_{p}-\rho\right) \frac{\pi}{6} d_{p}^{3} \mathbf{g},
$$

where $\rho_{p}$ is the droplet density, $\rho$ the gas density, $d_{p}$ the droplet diameter and $\mathbf{g}$ the gravitational acceleration. The aerodynamics force only includes drag force due to droplet density much higher than that of the gas $\left(\rho_{p}>>\rho\right)$ :

$$
\mathbf{F}_{p}^{A}=m_{p} \frac{1}{\tau_{p}}\left(\mathbf{u}_{p}-\mathbf{u}\right),
$$

where $\tau_{p}$ is the characteristic drag time. The latter is obtained thanks to the empirical correlation of Schiller and Naumann [38] for moderate values of the droplet Reynolds. For higher values, turbulence behind the droplet is fully developed, so the drag coefficient is constant.

The dispersed phase is loaded with droplets so that it impacts the gas behavior significantly but remains however sufficiently diluted to ensure that droplet/droplet interactions are negligible. This intermediate state can be modeled with a two-way coupling approach, i.e. a mutual interaction exists between droplets and gas but droplets cannot interact with each others. Thereby, $\mathbf{F}_{p}^{I}$ is null.

In addition to kinematics, the vaporisation of the droplets are numerically handled thanks to a mass transfer model proposed by Spalding [39], then enhanced by Abramzon and Sirignano [40], and offers different hypothesis in order to determine the thermodynamic properties (temperature, composition) of the droplet. More details can be found in Kuo [41] and Sirignano [42]. Droplets can contain different components, especially the kerosene as seen in Section 2.1.1, but this study only focuses on a single-component evaporation model.

Interactions of the dispersed phase with the sub-grid turbulence could impact the turbulence spectrum, mainly because the smallest droplets could dissipate the turbulence kinetic energy and the biggest ones could increase the turbulence. However, the spray of this study is not sufficiently dense and most of the recent studies use classical models [43, 44, 45]. In the same way, subgrid velocity fluctuations of the Eulerian phase could interact with the droplets. Such models are used when unresolved velocity fluctuations are of the same order of the droplets velocity or more important (for $S t<1$ in Elgobashi classification). Considering an evaporating spray, this case is encountered at the end of life of the droplets, i.e. when the droplets evaporate fast. In the present study, the main part of the spray can be considered as insensitive to sub-grid fluctuations [46, 47].

The full injection line and primary atomization at the injector exit are not modeled. Indeed, atomization is a complex phenomenon and calls into prohibitive CPU time. Instead, a polydisperse spray of kerosene droplets is directly injected [48]. Moreover, a simplified swirled injector model for the atomization, based on the FIMUR (Fuel Injection Method by Upstream Reconstruction) [49] model where a spray already established is assumed, is used. In the FIMUR model, 4 parameters need to be known: $R_{0}$ (the outlet radius of the injector), $\gamma_{s}$ (the mean angle of injection), $\dot{m}$ (the mass flow) and $A_{p}$ (a geometric parameter of the injector not always known). In the new model, named LISA (Liquid Injection for Swirled Atomizers), 3 parameters are required: $R_{0}, \gamma_{s}$ and $\dot{m}$. The difference between FIMUR and LISA lies in how the tangential velocity is determined. FIMUR links this velocity to the $A_{p}$ parameter and a radius that is equivalent to the center of the liquid sheet at the exit of the injector while LISA links directly the velocity to the mean cone angle [37].

\subsection{Solid solver}

As for the fluid phase, the conduction inside the solid walls is computed by YALES2, that also solves the heat equation over time. It is assumed that internal production does not exist and that the material is isotropic, i.e. thermophysical properties are constant if they are independent of the temperature. The heat conduction equation in a homogeneous material has been expressed by Fourier [50] in a linear form as:

$$
\frac{\partial T}{\partial t}=D_{t h} \nabla \cdot(\nabla T),
$$

where $D_{t h}=\lambda /(\rho c)$ is the thermal diffusivity coefficient of the material, showing its ability to modify its temperature under the influence of an external disturbance. $\rho$ is the material density, $c$ is the specific heat capacity on a per mass basis of the material, i.e. its ability to store energy, and $\lambda$ is the thermal conductivity of the material, i.e. its capability to transport heat. 
The equation is discretized with a Crank-Nicolson scheme and the time step $\Delta t$ is computed thanks to the Fourier number, which depends on the thermal diffusivity. The Crank-Nicholson scheme is unconditionally stable and the Fourier number can be chosen to be small enough to minimize the time integration errors and large enough to optimize the performances. This Fourier number is expressed as:

$$
F_{O}=\frac{\Delta t \times D_{t h}}{\Delta x_{\min }^{2}},
$$

where $\Delta x_{\text {min }}$ is the length of the smallest cell in the domain.

Crank-Nicolson is an implicit formulation and it implies to solve a linear system at each time step. This system is symmetric and can be solved thanks to a Deflated Preconditioned Conjugate Gradient [51].

\subsection{Coupling strategy}

For several years, combustion simulations in aeronautic systems did not take thermal exchanges between fluids and solids into account. Usually, these Conjugate Heat Transfer (CHT) are neglected in favor of analytical assumptions or experimentally-based correlations. However, in many practical situations, their use could be insufficient and could be a crude assumption because the two subdomains are intrinsically linked. Lately, in the aeronautical field, research efforts have been centered on the study of coupling hot burnt gases exiting the combustion chamber impacting a turbine blade in a RANS context. CHT simulations allowed to test the reliability of the innovative cooling systems, like studies of Luo \& Razinsky [52] or He \& Oldfield [53].

Nevertheless, York \& Leylek [54] have shown that the accuracy of the turbulent models impact the temperature distribution prediction inside the blade. Consequently, Duchaine [55] highlighted that LES coupling strategies are well-adapted to explore phenomena impossible to capture in RANS. Then, LES studies with CHT have been conducted in combustion chambers, like Jauré [56], and cooling systems with multi-perforated plates have been investigated (Florenciano [57], Scholl [58]). In the field of propulsion in general, Misdariis [59] showed that the CHT could be applied to piston engines, allowing to characterize the knock phenomenon.

\section{Exchanged variables}

Even if strong discontinuities exist on thermo-physical properties between the fluid and the solid parts, the principle of continuity implies that the heat flux $\phi$ and the temperature on both sides of the interface are equal all the time: $\phi_{s, b n d}=\phi_{f, b n d}$ and $T_{s, b n d}=T_{f, b n d}$, where subscripts $s, f$ and bnd denote solid part, fluid part and boundary, respectively. These two conditions allow to build interface conditions like Dirichlet-Dirichlet, where solvers impose their temperature, Neumann-Neumann, where solvers impose their flux, or Dirichlet-Neumann, where one solver imposes a flux, while the other imposes its temperature. During a synchronous study in physical time and for which coupling steps are done at each time step of each solver, Giles [60] indicates that the fluid has to send its flux and the solid its temperature in order to guarantee the numerical stability of the computation. This "natural" boundary condition is used in the present study.

\section{Synchronization events}

The present study aims at characterizing the mean heat transfer in the certification burner. A straightforward coupling strategy would be to exchange information between solvers when they both carry out the same physical time. This strategy is usually used when fluid and solid characteristic times are of the same order and is known as synchronous. However, in this study, the characteristic time scale of the solid is much larger than that of the fluid: this coupling strategy would imply to simulate a huge number of fluid time steps to reach a steady state on the solid side. This would be both extremely CPU expensive and useless from the fluid side. Another strategy has been adopted here: the solid is brought to steady state as fast as possible by diminishing its heat capacity to accelerate the transfers between the phases while guaranteeing that the correct steady state is reached. This methodology is also known as asynchronous coupling.

Besides this synchronization time, solvers can compute sequentially, one after another, or simultaneously. During a sequential coupling strategy, one solver is waiting for the other solver to send its information before running, and so on. On parallel machines, this kind of strategy is inefficient because many processors are idle during the simulation. So, a coupling strategy with solvers that 
Scheme legend:

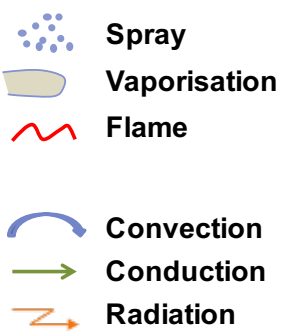

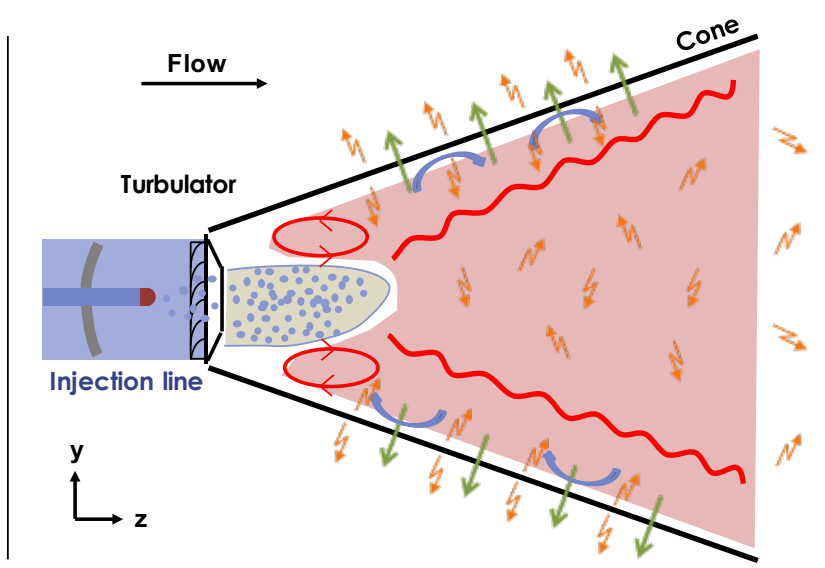

Figure 2: Schematic view of the certification torch with the involved phenomena.

advance in parallel allows to overcome this problem because the solvers run together using the information obtained at the previous coupling iteration. This method, used to study unsteady and steady phenomena, is adopted here. Readers may consult Felippa [61] or Duchaine [55] for further information about physical time and CPU time synchronization.

\section{Coupling code}

Coupling between solvers is carried out thanks to OpenPALM [62], a software developed by the CERFACS and ONERA [63]. It allows the simultaneous execution and the communication between different codes that were not created for this purpose. OpenPALM calls upon the CWIPI library that makes interpolations that are essential for the sending of variables when the two meshes are not coincident, i.e. the surface cells at the interface are not identical between the solvers.

\section{Fire-test computational set-up}

Section 1 introduced the certification burner and this section gives more details on the torch and its modeling. Gravity is oriented following the opposite direction of the the x-axis.

\subsection{Torch set-up and modeling description}

The certification torch is composed of three main parts: i) an injection line, where the moderately swirled air flows and the kerosene is injected, ii) a turbulator, that allows both to generate large turbulent scales and to stabilize the flame by creating a flow blockage, and iii) a cone, guiding the burnt gases. Figure 2 draws a simplified view of the multi-physic aspects that take place inside the cone. The injector sprays the kerosene droplets inside the cone and then droplets evaporate and burn. The flame grows from the turbulator to the exit of the cone and recirculation zones appear near the corners of the turbulator. Heat transfers also take place in the cone:

- forced convection of the flame on the wall,

- conduction inside the solid,

- radiative heat transfer of the burnt gases, soot and walls.

The present study only focuses on CHT of the convection and the conduction. Figure 3 shows the modeling of this burner, the different parts previously described and its dimensions. The cone is modeled according to the ISO norm 2685 [2]. The modeling of the turbulator is based on measurements taken from the real apparatus. Figure 4 compares pictures of the experimental equipment and its modeling for two different views.

All simulations are performed on unstructured tetrahedral grids. The burner is placed in a fluid computational domain of about $3 \mathrm{~m}$ on each side and presented Fig. 5. It contains 40 million tetrahedral cells. Figure 6 gives details of the mesh sizes, with a cell size between 0.8 and $2 \mathrm{~mm}$ inside the burner and 2.5 to $3 \mathrm{~mm}$ for the burnt gases area at the exit of the cone. Due to the 
slimness of the cone and the fact that at least four cells are required to capture the thermal gradient in the cone walls, the mesh of the solid consists of 140 million cells from $0.2 \mathrm{~mm}$ in the cone to 1 $\mathrm{mm}$ in the injection line. However, it is not a problem because the solving of the heat equation is almost negligible compared to the fluid solver.

Solid and fluid grids are non-coincident, as shown in Fig. 7, which implies special care in the interpolations used to exchange information between solvers: a filtering procedure based on a smoothing operator, as defined by Shapiro [64], is performed to avoid aliasing. This operator is conservative to preserve the total heat flux sent by the fluid solver. It is also used to filter the temperature sent by the solid solver as the solid mesh is finer than the fluid mesh in some regions.

\subsection{Data settings and boundary conditions}

Two numerical cases are investigated, an adiabatic and a CHT computation. The fluid mesh resolution leads to a wall-normal mesh resolution $y^{+} \approx 90$ in wall units. As such, wall-modeled LES is performed [65]. The wall model is based on a standard log-law model. The combination of the TFLES model with a wall model in the case of a CHT simulation has never been validated for flame/wall interactions and it is out of the scope of the present study. As it will be shown later, flame/wall interactions are limited.

A small co-flow of fresh air at ambient temperature is injected to ensure proper boundary conditions. Fresh air is injected in the injection line of the torch with a swirled velocity profile obtained

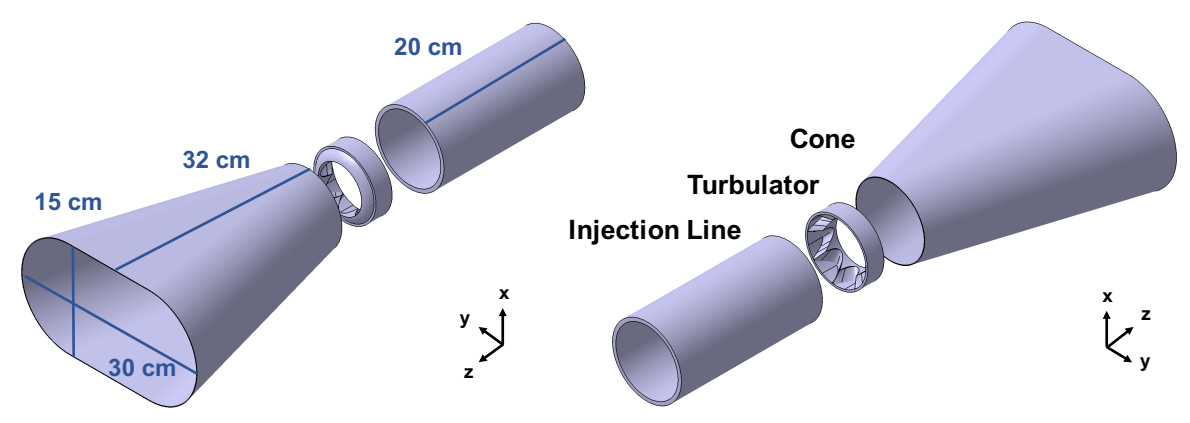

Figure 3: Exploded view of the certification torch with dimensions of the injection line and the cone

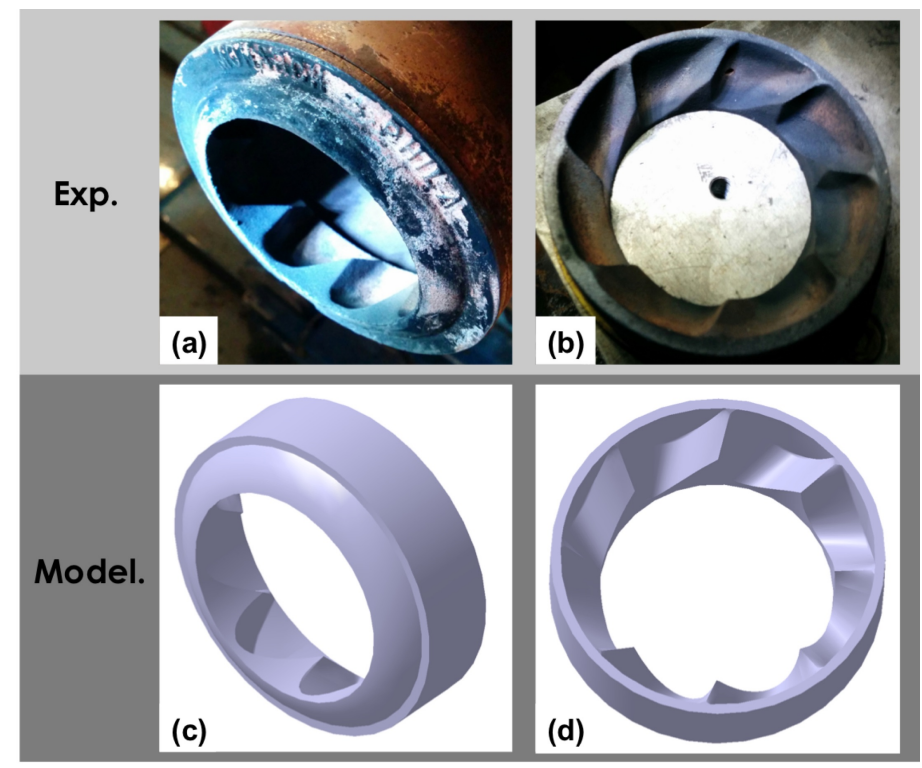

Figure 4: Details of the experimental turbulator on the top line and its modeling at the bottom line, for its front ((a) and (c)) and rear ((b) and (d)) views 


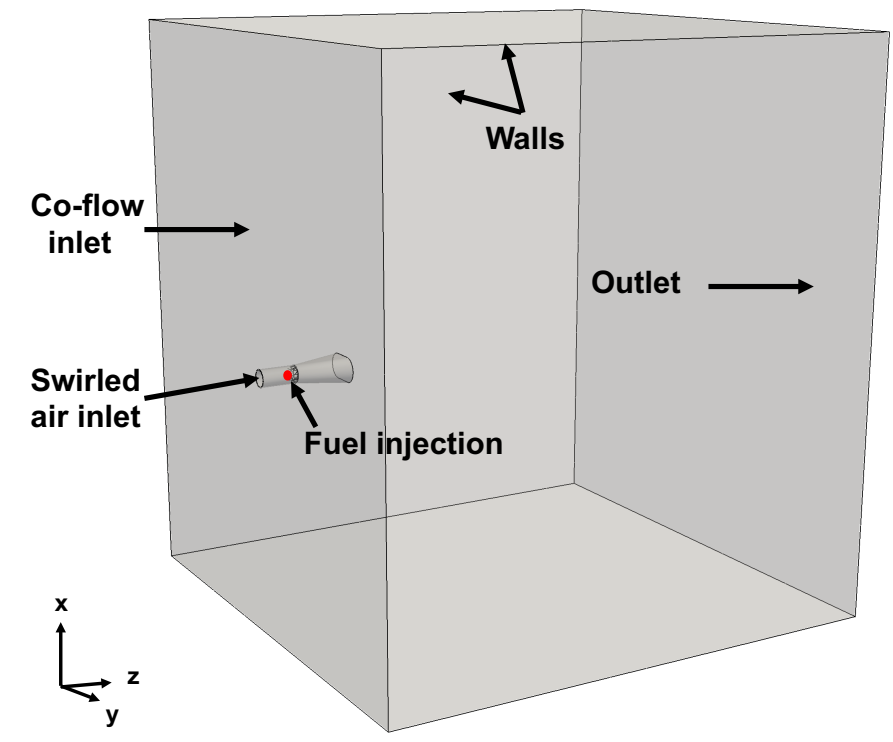

Figure 5: Computational fluid domain with boundary conditions

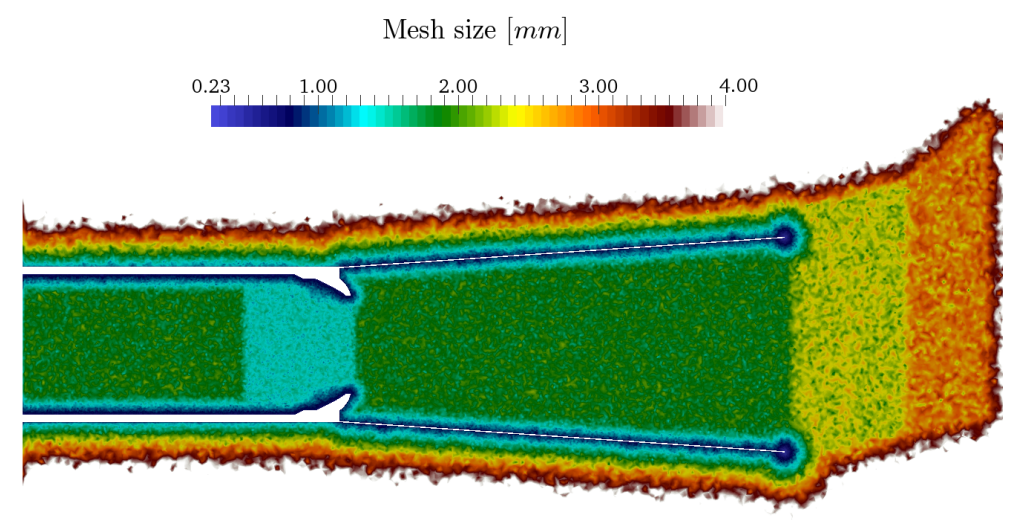

Figure 6: Fluid mesh sizes of the torch in the vertical plane

experimentally. The velocity profile was measured by disassembling the torch and performing PIV. The mean Reynolds number, based on the diameter of the turbulator, is about 30700; the flow is turbulent. Similarly, the liquid phase velocity profile is set from experimental data. A calibration is done so as to determine the numerical Rosin-Rammler diameter distribution of the fuel droplets. Two Stokes number have been computed based on: 1) the length of the cone: $S t$ is around 1, 2 ) the size of the recirculation zones: $S t$ is around 20. The mean convective time based on the volume of the cone is $\tau_{f} \approx 260 \mathrm{~ms}$. Numerically, the stability criteria (CFL $=0.6$ and Fo $=0.15$ ) impose a time step of $\Delta t_{f} \approx 4.510^{-6} \mathrm{~s}$. The solid metal is Inconel, and its characteristic time is $\tau_{s}=0.2 \mathrm{~s}$ with a time step $\Delta t_{s} \approx 5.3 \mathrm{~ms}$. To converge the temperature field quicker inside the cone, the diffusivity $D_{t h}$ has been multiplied by four by dividing the heat capacity by four, so that the characteristic time becomes $\tau_{s}=40 \mathrm{~ms}$. After convergence, this coefficient was imposed at its physical value. Coupling iterations are set all the 320 iterations in the fluid for 40 iterations in the solid with 1024 cores for the fluid and 60 cores for the solid. The solid has been initialized using an ambient temperature in the injection line and a temperature that gradually increased from the turbulator to the exit of the cone, with a mean temperature of $T=1000 \mathrm{~K}$. The convergence has been reached when mean and maximum temperatures inside the cone were stable.

During the calculations, an accumulation of droplets appeared at the end of the injection line, which indicates a probable formation of a liquid film at the wall. In the simulation, these droplets tend to accumulate at the bottom side of the turbulator due to gravity but they cannot form any film as droplet/droplet interactions are not considered here. To remedy this situation, the filming 


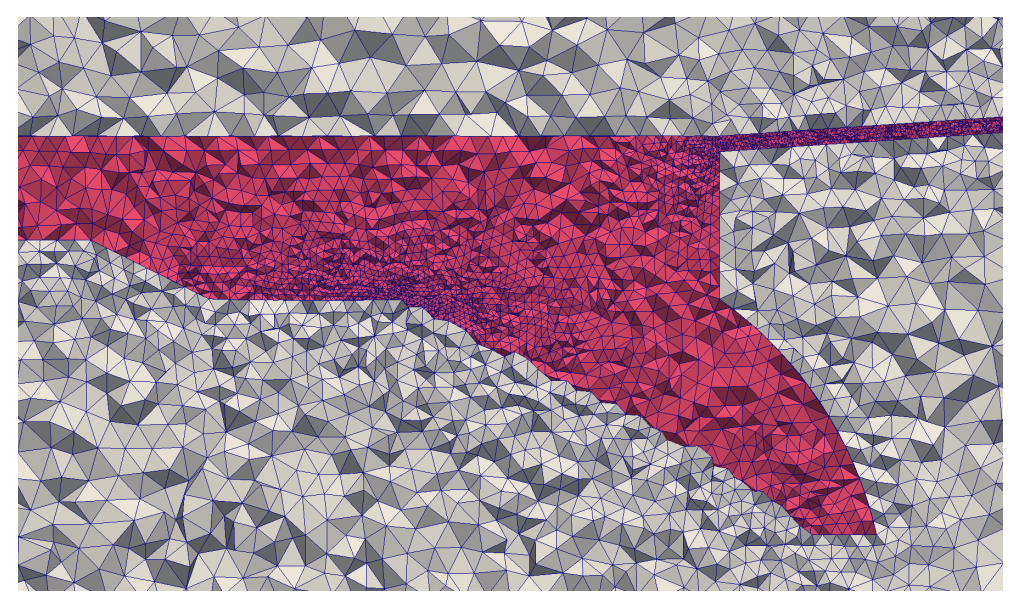

Figure 7: Details of fluid (in gray) and solid (in red) meshes around the turbulator

droplets are suppressed and re-injected without velocity all around the turbulator lip. Each droplet owns a residence time that corresponds to its life time. The filming droplets are identified as those which have a residence time long enough, i.e. more than $100 \mathrm{~ms}$. The re-injection is modeled via a normal distribution between 0 and 1 , for which the formulation is:

$$
f(x)=\frac{1}{\sigma \sqrt{2 \pi}} \exp \left(-\frac{1}{2}\left(\frac{x-\mu}{\sigma}\right)^{2}\right),
$$

where $\mu$ is the mean of the distribution and $\sigma$ the standard deviation. This re-injected liquid volume represents about $14.3 \%$ of the injector flow, which is not negligible and may have an impact on the equivalence ratio distribution, and therefore on the flame. However, it indicates that most of the droplets do not interact with the walls.

Computations were performed on 45 nodes of the super-computer Occigen of the CINES in Montpellier, France, using Intel Xeon Broadwell microarchitecture. 24 hours of Eulerian solver simulation is equivalent to $160 \mathrm{~ms}$ of physical time, i.e. half a convective time. To reach a converged state, between 40 and 50 simulations have been performed, which represents 20 seconds of physical time for the solid. This long accumulation time illustrates the challenge of performing such multiscale simulation.

\section{Results and discussions}

This section presents the flame structure in an adiabatic case and compares the results obtained in adiabatic and CHT cases. In this section, legends are shown without numerical values for confidentiality reasons.

\subsection{Flow and flame topology}

As a first step, the topology of the flame is investigated considering only the adiabatic case. Figure 8 shows the droplets spatial distribution inside the burner. The small droplets follow the injection line air flow, while the droplets with intermediate diameter, in green and yellow, take place at the periphery of the cone. This segregation is due to the different Stokes number of the individual droplets. As a result, the smallest droplets in blue are those which penetrate the farthest, and then evaporate at the middle of the cone. Like indicated previously, the biggest ones, in orange and red, stream along the turbulator and are re-injected at the turbulator lip. The spray mainly evaporates when entering the flame front. A small part of the spray crosses the flame front to reach the inner wall of the cone where it evaporates slowly. These rich zones close to the wall allow the flame front to be fed again with evaporated kerosene, leading to the presence of diffusion flames. This point will be further discussed below.

Figure 9 presents the instantaneous and mean fields of velocity: figures in the upper part correspond to a vertical planar cut while pictures at the bottom to an horizontal planar cut. The 


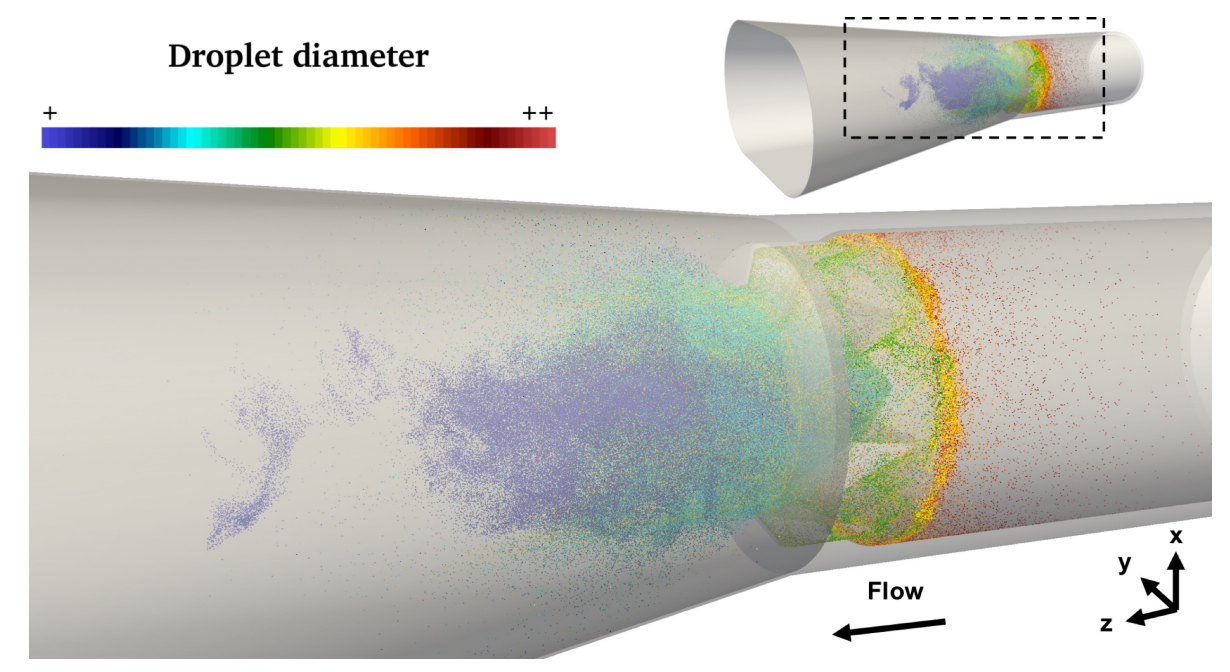

Figure 8: Instantaneous field of the Lagrangian phase colored by the diameter of the droplets w/o coupling
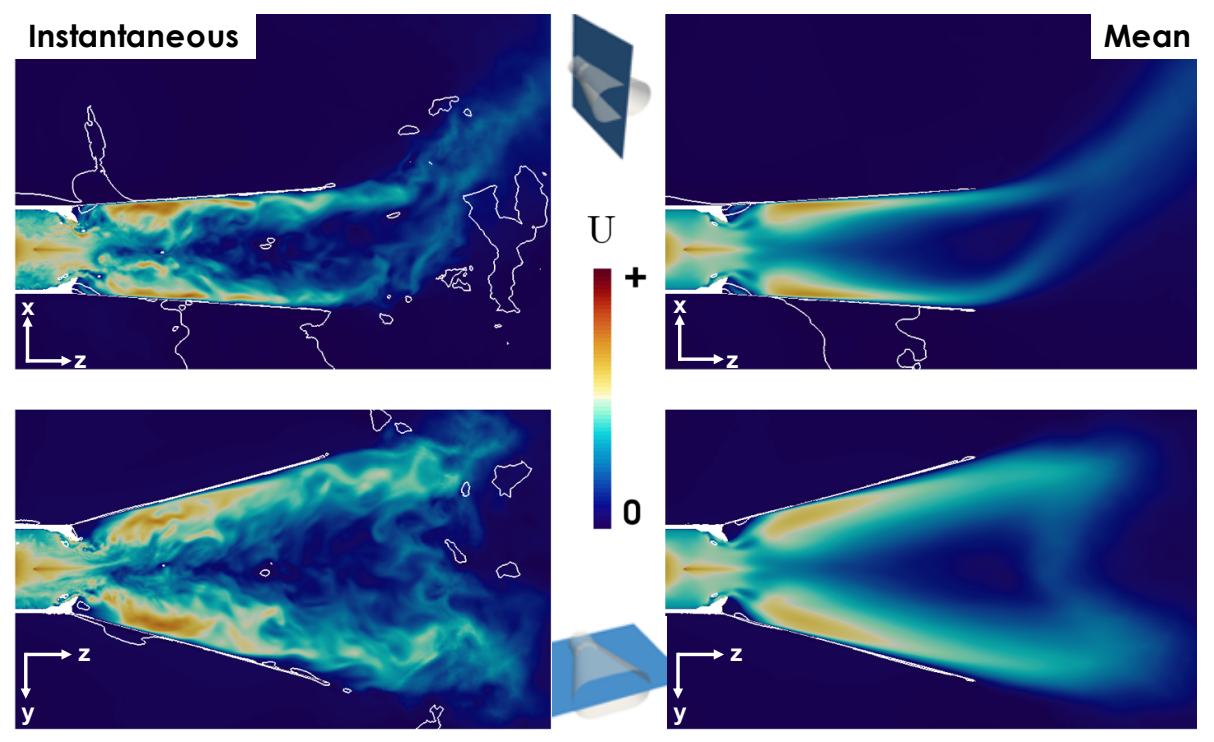

Figure 9: Instantaneous (left column) and mean (right column) fields of velocity w/o coupling, with contours of recirculation zones in white 

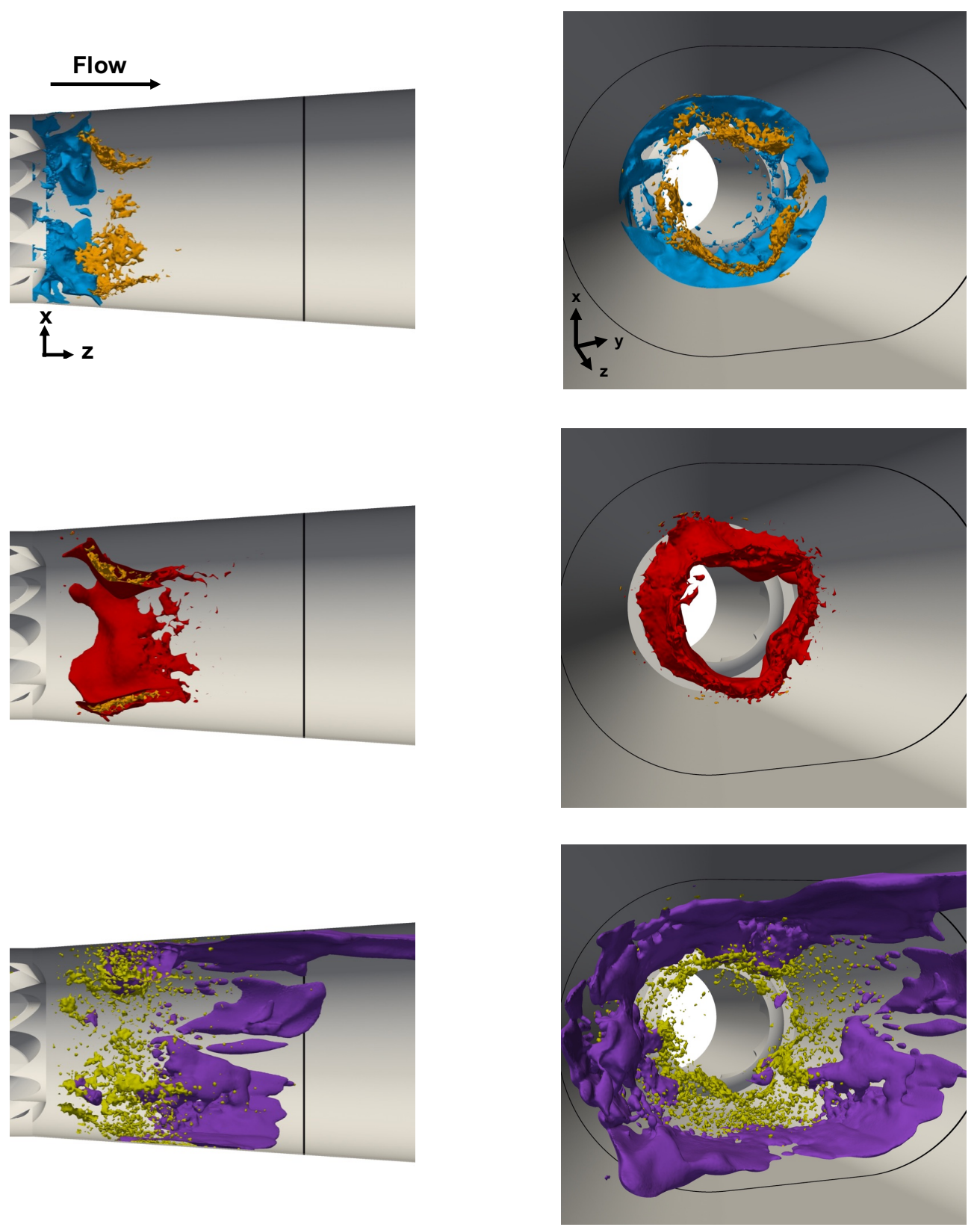

Figure 10: Instantaneous iso-contour fields of side (left) and front views (right) in an adiabatic case. The black line indicates the middle of the cone. Blue: zero axial velocity, orange and yellow: source terms of kerosene for negative (reaction) and positive (production) values, red: heat release, purple: mass fraction of kerosene

highest velocity areas are situated close to the wall, in the first part of the cone. A separation of the flow from the wall can be seen at the end of the cone. Inside the cone, this effect is very limited due to thermal expansion. Recirculation zones are visible next to the turbulator. This backflow allows to heat up the air flow and the spray. Droplet evaporation occurs mainly close to the turbulator, where the heat release becomes high and where the flame stabilizes.

Figure 10 illustrates how the flow develops inside the cone and how the aerodynamics affects the flame. First of all, the zero axial velocity in blue, which materializes the recirculation zones like mentioned in Fig. 9, informs that an Outer Recirculation Zone (ORZ) takes place at the exit of the turbulator. In this ORZ, burnt gases recirculate and allow to preheat fresh gases. Representative value of negative source term of kerosene is indicated by orange spots and informs about fuel consumption, located immediately after the ORZ. It exactly corresponds to the place where the flame is the strongest since the source term of sensible enthalpy, in red, totally wraps 
the kerosene consumption area. It can be noticed that the flame features large-scale wrinkles due to the turbulator. Indeed, the shape of the lobes is found in the topology of the reactive zone. It also coincides with the evaporation of fuel droplets represented by iso-surfaces of positive source term of kerosene in yellow. This evaporation of droplets gathered in group in the center can be distinguished from individual droplet evaporation at the wall, where the droplets are big enough to cross the flame front. Finally, the purple shapes reveal that a lot of gaseous kerosene is always present along the cone wall, and even in the second part of the burner, due to the evaporation of individual droplets.

\subsection{Comparison between adiabatic and CHT cases}

In this section, comparisons between adiabatic and CHT simulation are carried out. Numerical results are displayed like in Fig. 9 for different studied fields. The adiabatic case is showed on the left-hand side of the figure and the CHT case on the right-hand side.

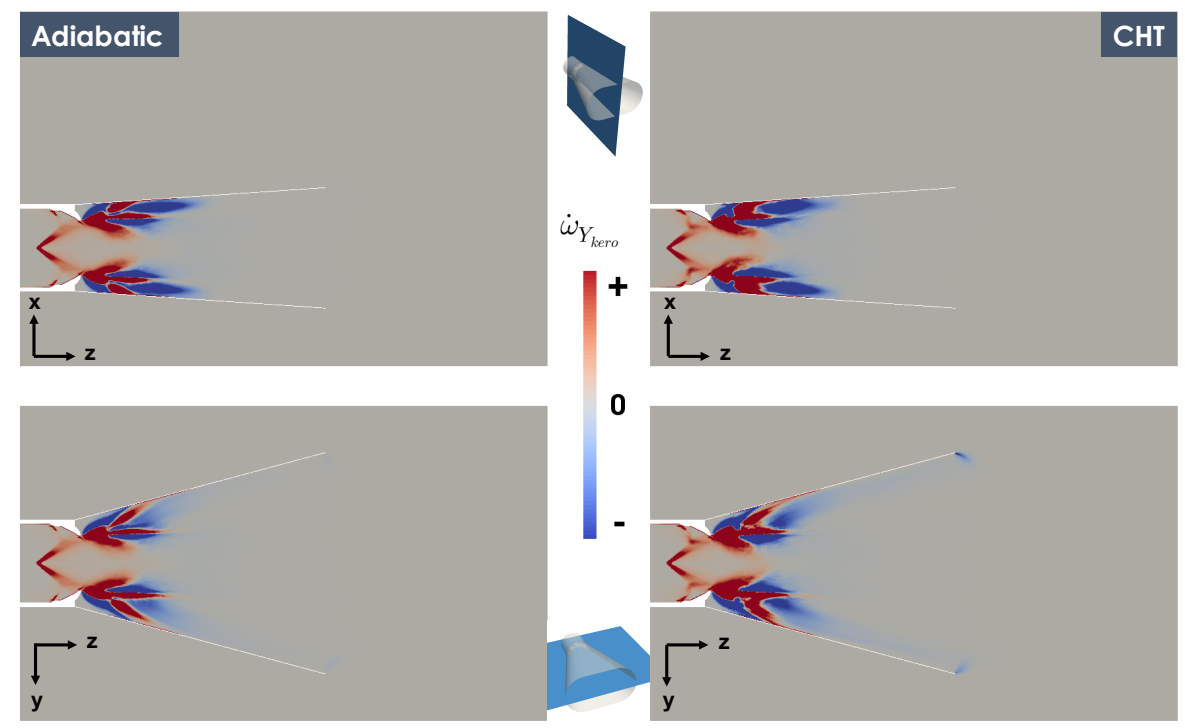

Figure 11: Mean field of mass fraction source term

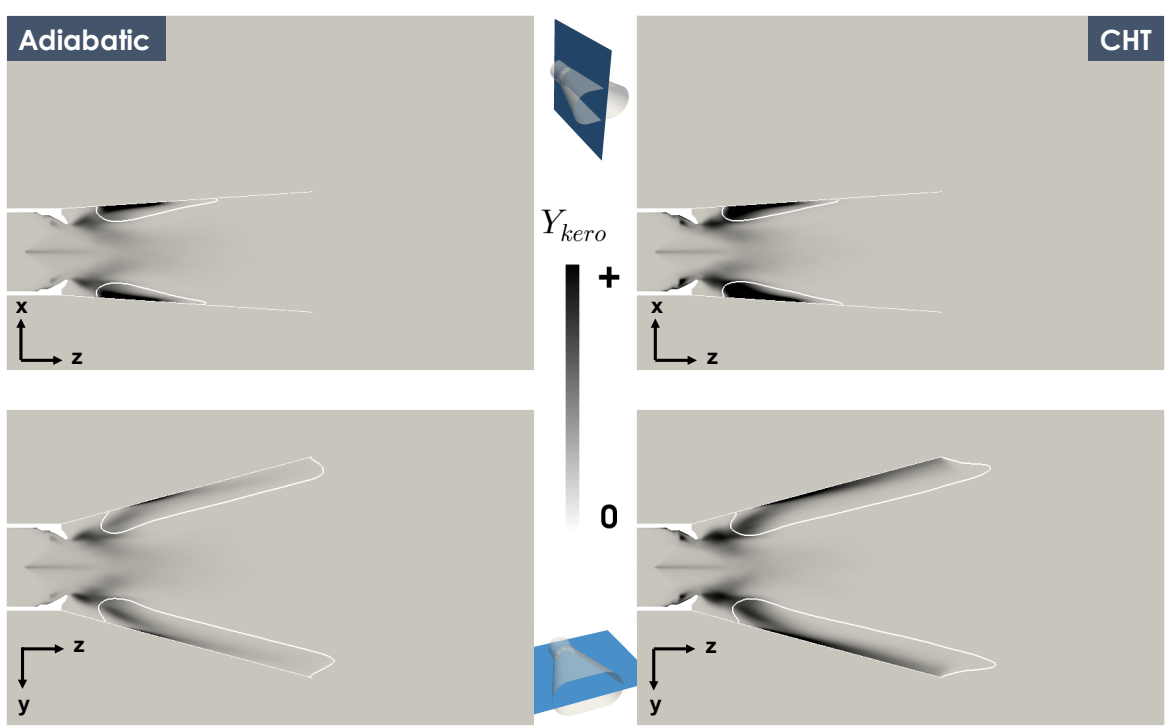

Figure 12: Mean field of mass fraction with stoichiometric line 

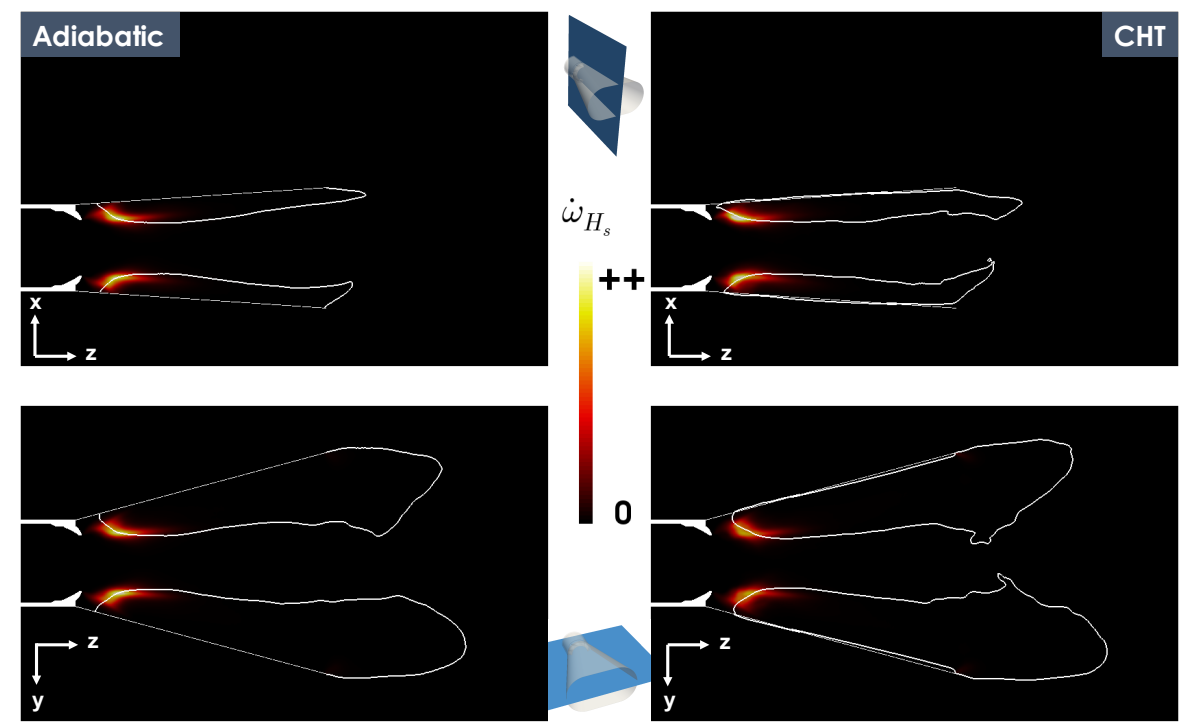

Figure 13: Mean field of sensible enthalpy source term with iso-contour of temperature $T=1800 \mathrm{~K}$
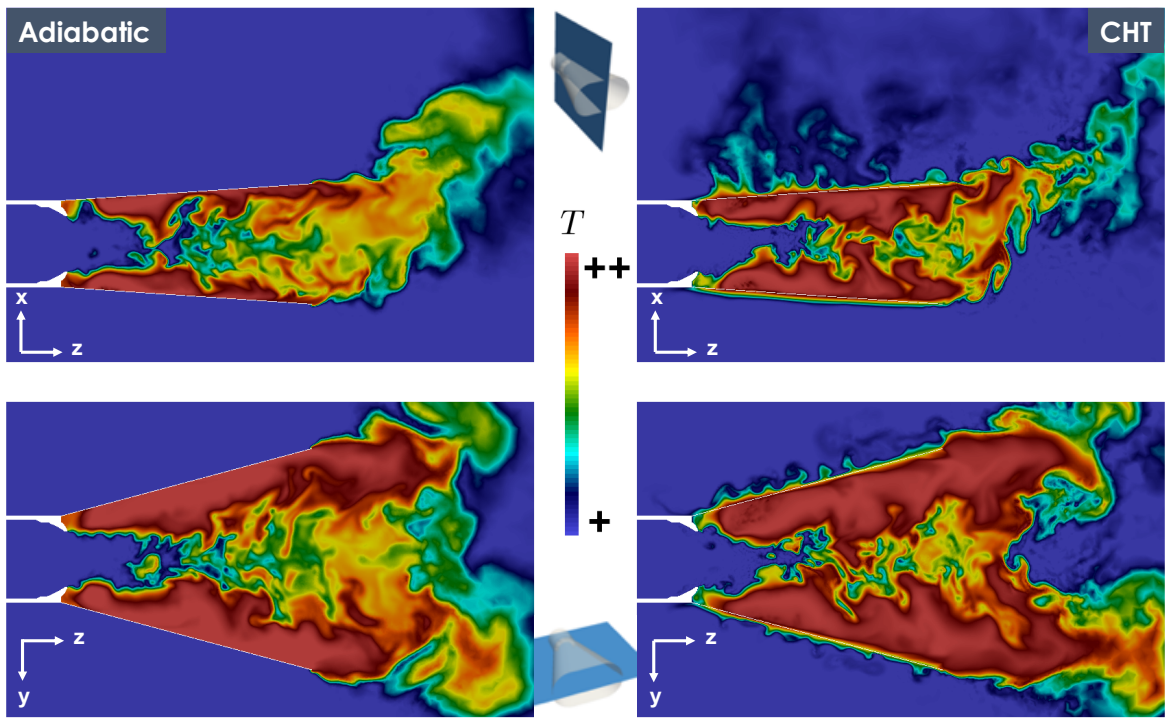

Figure 14: Instantaneous field of temperature 
Figure 11 highlights the creation of gaseous kerosene inside the turbulator lobes in the CHT simulation. In this case, this evaporation of liquid at the outlet of the turbulator fades for the benefit of the consumption of fuel that becomes more and more important in the ORZ. There is also a larger amount of gaseous fuel consumption at the walls and at the edge of the cone outlet. The presence of kerosene at the walls and inside the turbulator, as shown in Fig. 12, indicates the importance of taking the conduction in the solid into account. Indeed, without radiative heat transfer to evacuate the heat to the outside, the wall temperature is very high leading to warm gases. The same figure features the line of stoichiometric combustion. The surrounded rich zone is more important, especially in the vertical plane where the line progresses towards the main air flow and the outlet of the cone. In Fig. 13, the most reactive area is slightly hotter in the adiabatic case. The Fig. shows that large-scale flame wrinkling seems to be unaffected by CHT. The topology of the flame is wrinkled along the air stream as seen in the instantaneous fields of temperature of Fig. 14. In adiabatic case, as well as CHT configuration, buoyancy effects are observed at the outlet of the torch. But taking into account the CHT, additional hot air plume buoyancy is created at the torch wall due the hot temperature of the cone.

The presence in larger quantity of kerosene at the walls in the coupled heat transfer simulation, as well as the more important values of its consumption at the edge of the cone outlet, leads to plot a volume rendering of the sensible enthalpy source term in a CHT case Fig. 15. Left figure shows an instantaneous field of the flame topology inside the burner. Like in the adiabatic case, the flame features large-scale wrinkling due to the shape of the turbulator, as presumed in Fig. 13, and isolated hot spots are noticeable. On the right hand side, the moderate values of enthalpy source term inside the turbulator shows that the hot wall temperature helps evaporating droplets flowing inside the turbulator lobes besides pre-heating the cold fresh air. For moderate values of the enthalpy source term, i.e. in the slowly reacting regions, one can see slow-burning of gases at the outlet of the torch.
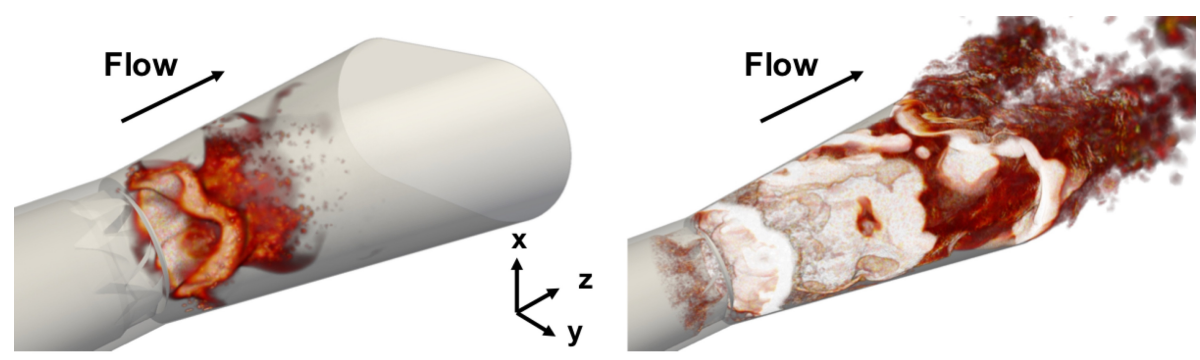

Figure 15: Instantaneous volume rendering for high (left) and moderate values (right) of the sensible enthalpy source term $\overline{\dot{\omega}}_{T}$ in a CHT case. Colors go from black (low values) to white (high values) through red

The analysis of the flame topology does not provide any information about the combustion regime. Even if fuel and oxidizer are jointly injected, kerosene is primarily in liquid state and the mixing between phases can not operate. So premixed or non-premixed combustion may take place inside the burner. Distribution of Flame Index FI inside the flame zone gives some information about these regimes. Flame index is calculated as:

$$
\mathrm{FI}=\frac{1}{2}\left(1+\frac{\nabla Y_{F} \cdot \nabla Y_{O}}{\left|\nabla Y_{F}\right|\left|\nabla Y_{O}\right|}\right) .
$$

When $\mathrm{FI}=0$, fuel and air fluxes are in opposite directions, corresponding to the diffusion regime, while when $\mathrm{FI}=1$, fuel and air fluxes are in the same direction, corresponding to the perfectly premixed regime.

This distribution of FI is plotted in Fig. 16 for different spatial ranges of the flame inside the torch: i) the first quarter, where the most reactive zone is, ii) the second quarter and iii) the second half of the cone, where gaseous kerosene is present at the wall. In both adiabatic and CHT cases, average has been performed on twenty instantaneous solutions, covering half a convective time based on the volume of the cone.

The adiabatic case reveals a balance between premixed and non-premixed regimes nearly at the same level in each part of the cone. Intermediate values exist and correspond to a wide range of partially premixed flames. In the third part of the cone, the levels of canonical forms are higher 

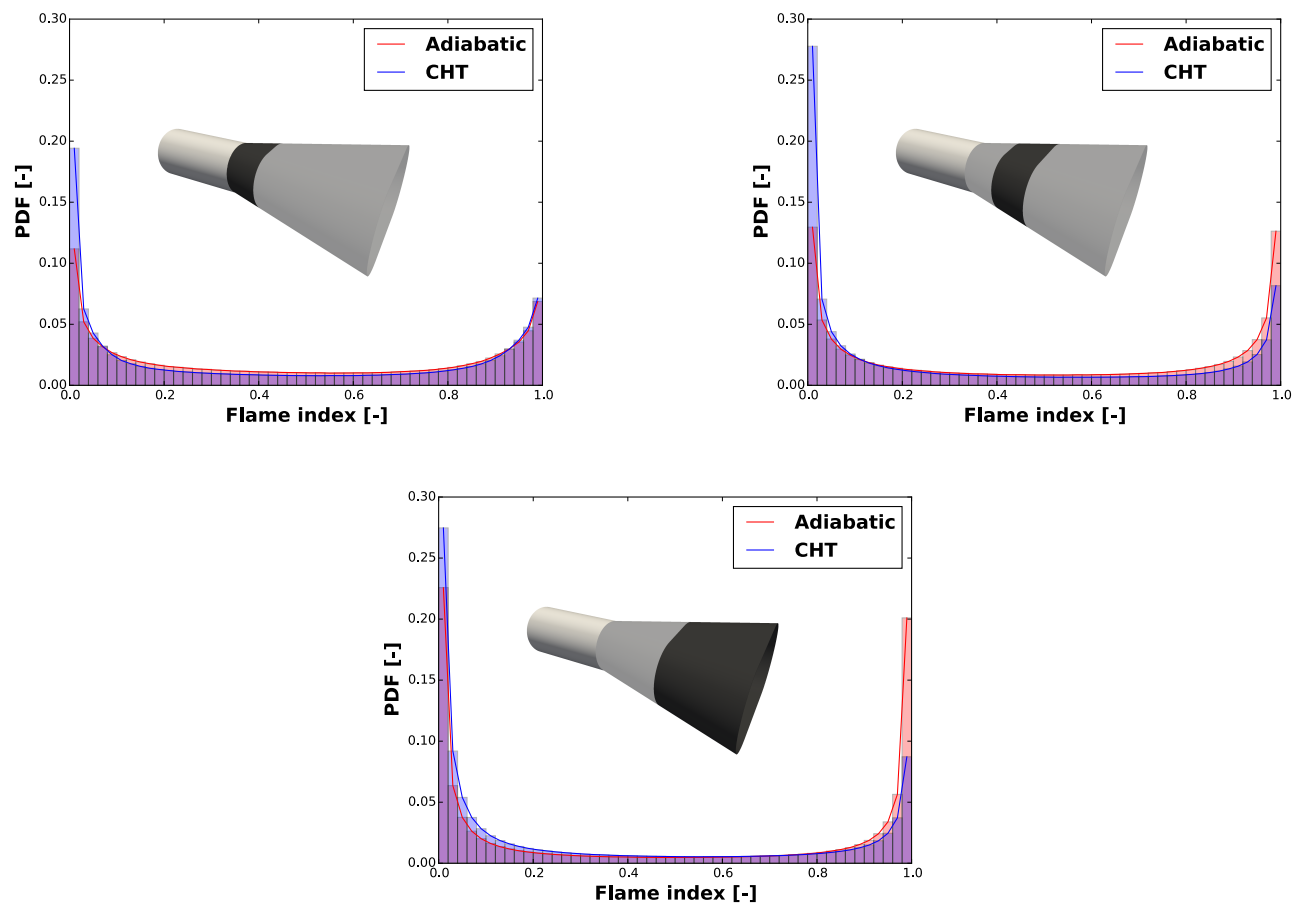

Figure 16: Flame index inside the cone with and without coupling simulation, for three different positions
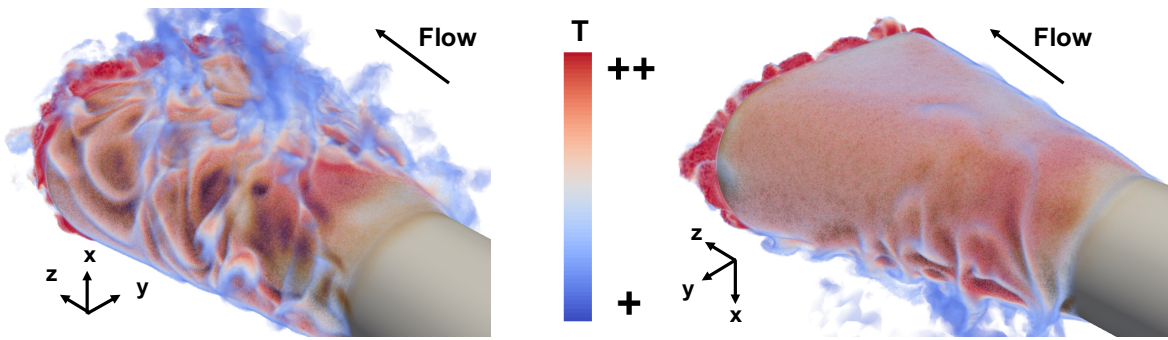

Figure 17: Instantaneous volume rendering of the air surrounding the torch for the upper (left) and the lower side (right)

since the remaining gaseous kerosene is mixed by turbulence, increasing the presence of premixed fronts, and some isolated fuel pockets, thrown up against the wall, burn in non-premixed regime. The CHT case indicates that the flame is predominantly in non-premixed regime throughout the cone. The probability of being in this regime is high in the second and the third parts of the torch, and coincides perfectly with the consumption of gaseous kerosene observed in Fig. 11. This significant difference shows that the CHT has a real impact on the combustion regime.

\subsection{Heat losses to the outside}

Flow around the horizontal torch

Figure 17 better illustrates the flow around the torch oriented horizontally. The air is heated at the wall and has a different behavior above and below the cone. Above, the temperature gradient induces a hot plume: the temperature of fresh air increases and elevates. However below the torch, a stable stratification is obtained due to the negative temperature gradient. The Rayleigh number $R a$, associated with buoyancy-driven flow, is about $6 \times 10^{6}$ in this configuration.

This different thermal behavior above and below the cone leads to different wall heat losses on the cone: heat flux is more important at the upper side and represents $56 \%$ of the total. The wall heat flux on the cone can be compared to the total flux at the exit of the torch: it represents only $2 \%$ of the exit enthalpy flux. 


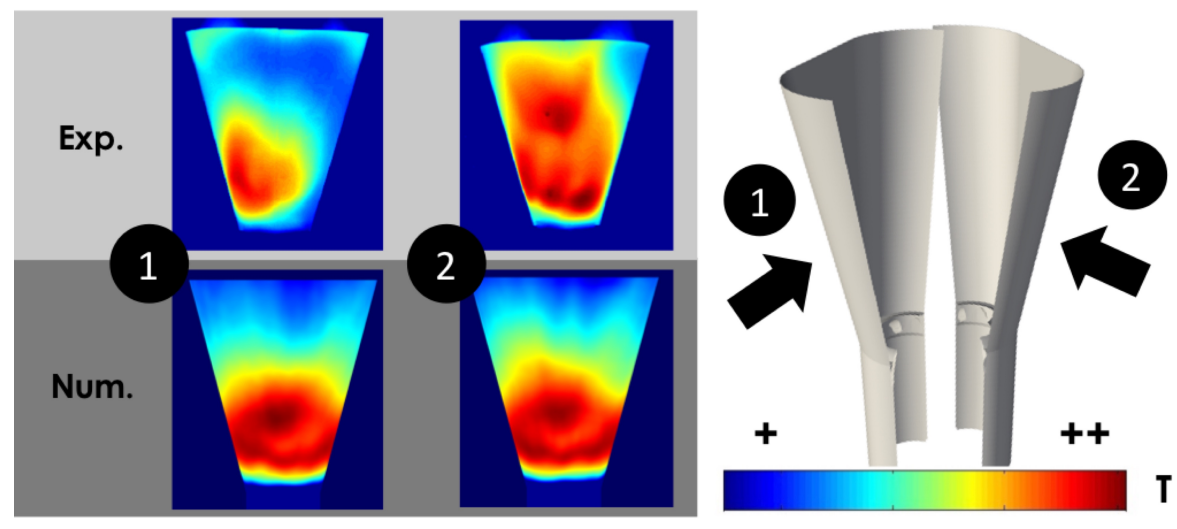

Figure 18: Qualitative comparison of the cone temperature profile between experimental (top) and numerics (bottom) for the two sides of the torch placed vertically

\section{Comparison of the vertical torch to experiment}

In classical fire demonstrations, the torch is placed horizontally, as it was the case in the previous calculation. However, a test to obtain the experimental field temperature on the cone has been performed placing the torch vertically to ease the optical diagnostics. As a matter of fact, a new simulation has been performed orienting the torch as in the experimental conditions. The CHT computation enables to access to this temperature distribution, as shown in Fig. 18, even if the lack of radiative heat loss on the solid wall in the simulation leads to an over-prediction of this temperature. A fairly good qualitative agreement between the numerical data and the experiments is obtained in the part (1). A hot zone is observed experimentally on this side, while the hot region seems to expand in the second part of the cone in the opposite side (2). Numerically, both sides owns a hot zone and are almost identical. Despite the fact that a symmetry is expected as observed in the numerical case, the experimental heat flux exhibits an asymmetry which may be due to a misalignment of the burner parts or might be due to some fluctuations of the operating conditions. Indeed, experimental pictures of the inside of the cone reveal a strong deposit of soot on one side, while the deposit on the other side is slighter. This asymmetric deposit may be due to a misalignment of the injector with respect to the turbulator. In this condition, the biggest droplets, that originally hit the turbulator lobs due to segregation, are able to directly enter into the cone. Their size allows them to cross the flame front and they are able to burn in diffusion regime at the wall, resulting in soot production on the wall.

To confirm the symmetry of the simulation, temperature of the cone and wall heat flux inside the torch are plotted along the axis of the cone in Fig. 19. Statistics have been collected during $150 \mathrm{~ms}$. Temperature and flux are normalized as follows:

- temperature: $T^{*}=(T-<T>) /\left(<T>-T_{F G}\right)$, with $<T>$ the global mean temperature of the cone and $T_{F G}$ the temperature of the fresh gases;

- heat flux: $\phi^{*}=\phi /\langle\phi\rangle$, with $\langle\phi\rangle$ the global mean heat flux of the cone.

The temperature along the cone is almost the same for both sides, except for the second part of the torch where a slight difference of $30 \mathrm{~K}$ at most exists. One can see an increase of the temperature at the exit of the cone, due probably to slow-burning previously discussed. The same remarks can be made about the heat flux, even if differences in the second part of the cone are more pronounced due to a lack of statistics accumulation.

\section{Conclusion and perspectives}

First, it has been shown that CHT calculation can be performed to model confined flame through the coupling of flow and solid solvers. This procedure has been applied on a certification torch in order to better understand the flow physics that takes place inside the burner. It appears that LES is a useful tool to model this kind of complex reactive flow as it takes into account the unsteadiness of the flow, which is important for the mixing and heat transfer. A comparison 

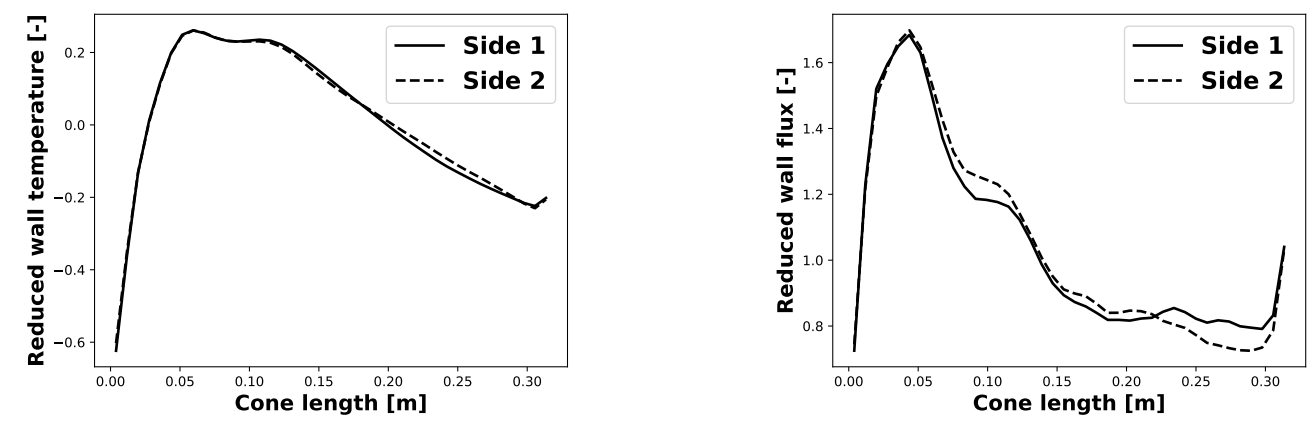

Figure 19: Reduced wall temperature and wall heat flux along the cone for both sides

between adiabatic and CHT simulations proved that the flame topology, as well as the combustion regime, are different. Indeed, in this kind of device, all heat transfer types are important in order to have a good prediction of the flame stabilization and of the heat flux at the exit of the torch. Finally, a comparison with experimental data permitted to support the fact that, even if convection is dominant when impinging equipments, radiative heat transfer is necessary to correctly predict the temperature field of the cone and thus the topology of the flame. So, a special care is needed to take into account all the heat transfer.

Our future work will focus on the influence of the radiative heat transfer by coupling it with the fluid and solid simulations. The numerical developments started by Nguyen [66] offers a basis to simulate a convection / conduction / radiation-coupled heat transfers on the certification torch. The burner wall, as well as and the heat flux and temperature obtained when the flame is applied on a calorimeter, will be compared to the adiabatic simulations. A mesh refinement sensitivity analysis will also be carried out in order to quantify the mesh dependency. The LES model of the burner will finally be applied to the prediction of heat transfer in an impacting flame configuration: a well instrumented metal plate placed in vicinity of the burner will be investigated as a simplified test case.

This work was granted access to the HPC resources from CINES (Centre Informatique National de l'Enseignement Superieur), from IDRIS (Institut du Developpement et des Ressources en Informatique Scientifique) and from TGCC-CEA under the allocations x20172b6880 made by GENCI (Grand Equipement National de Calcul Intensif). It was also granted CPU time by CRIANN under the allocation 2012006.

The authors declare that they have no conflict of interest.

\section{References}

[1] Certification specifications for engines. Annex to ED Decision 2010/015/R Amendment 3. European Aviation Safety Agency (2010).

[2] ISO 2685:1998: Aircraft - environmental conditions and test procedures for airborne equipment - resistance to fire in designated fire zones. Technical report, The International Organization for Standardization (ISO) (1998).

[3] US Department of Transportation. Powerplant installation and propulsion system component fire protection test methods, standards and criteria. Technical report, Federal Aviation Administration: Advisory Circular (AC) (1990).

[4] Ochs R.I.: Design and Analysis of the Federal Aviation Administration Next Generation Fire Test Burner. PhD thesis at Rutgers University, USA (2013).

[5] Le Neve S.: AC20-135/ ISO 2685, Fire tests on components used in fire zones. Comparison of gas burner to oil burner. Proc. of the FAA Materials Meeting, Atlantic City (2008).

[6] Tranchard P., Samyn F., Duquesne S., Thomas M., Estèbe B., Montès J.L., Bourbigot S.: Fire behaviour of carbon fibre epoxy composite for aircraft: Novel test bench and experimental study. J. Fire Sci., 33(3), 247-266 (2015). 
[7] Kao Y.H., Tambe S.B., Ochs R., Summer S., Jeng S.M.: Experimental study of the burner for FAA fire test: NexGen burner. Fire Mater., 41(7), 898-907 (2017).

[8] Neely A., Ireland P.: Pilot study to investigate novel experimental and theoretical fire-event modelling techniques. AIAA, 37th ASME, 99-0326 (1999).

[9] Sikoutris D.E., Vlachos D.E., Kostopoulos V., Jagger S., Ledin S.: Fire burnthrough response of CFRP aerostructures. Numerical investigation and experimental verification. Appl. Compos. Mater., 19(2), 141-159 (2012).

[10] Grange N., Chetehouna K., Gascoin N., Senave S.: Numerical investigation of the heat transfer in an aeronautical composite material under fire stress. Fire Saf. J., 80, 56-63 (2016).

[11] Moureau V., Domingo P., Vervisch L.: Design of a massively parallel CFD code for complex geometries. C. R. Mécanique, 339, 141-148 (2011).

[12] Pierce C.D., Moin P.: Progress-variable approach for large eddy simulation of non-premixed turbulent combustion. J. Fluid Mech., 504, 73-97 (2004).

[13] Chorin A.J.: Numerical solution of the Navier-Stokes equations. Math. Comput., 22(104), 745-762 (1968).

[14] Kim J., Moin P.: Application of a fractional-step method to incompressible navier-stokes equations. J. Comput. Phys., 59(2), 308-323, (1985).

[15] Kraushaar M.: Application of the compressible and low-mach number approaches to LargeEddy Simulation of turbulent flows in aero-engines. PhD thesis at CERFACS of Toulouse, FRANCE (2011).

[16] Edwards T., Maurice L.Q.: Surrogate mixtures to represent complex aviation and rocket fuels. J. Propul. Power, 17(2), 461-466 (2001).

[17] Orain M., Baranger P., Ledier C., Apeloig J., Grisch F.: Fluorescence spectroscopy of kerosene vapour at high temperatures and pressures: potential for gas turbines measurements. Appl. Phys. $B, \mathbf{1 1 6 ( 3 )}, 729-745$ (2014).

[18] Rachner, M.: Die Stoffeigenschaften von Kerosin Jet A-1. DLR-Mitteilung, 98-01, 152 (1998) [in German].

[19] Vovelle C., Delfau J.L., Reuillon M.: Formation of aromatic hydrocarbons in decane and kerosene flames at reduced pressure. Soot Formation Combust., 50-65 (1994).

[20] Riesmeier E., Honnet S., Peters N.: Flamelet modeling of pollutant formation in a gas turbine combustion chamber using detailed chemistry for a kerosene model fuel. J. Eng. Gas Turbines Power., 126(4), 899-905 (2004).

[21] Balès-Guéret C., Cathonnet M., Boettner J.C., Gaillard F.: Experimental study and kinetic modeling of higher hydrocarbon oxidation in a jet-stirred flow reactor. Energy Fuels, 6(2), 189194 (1992).

[22] Elliott L., Ingham D.B., Kyne A.G., Mera N.S., Pourkashanian M., Whittaker S.: Reaction mechanism reduction and optimisation for modelling aviation fuel oxidation using standard and hybrid genetic algorithms. Comput. Chem. Eng., 30(5), 889-900 (2006).

[23] Slavinskaya N.A., Zizin A., Aigner M.: On model design of a surrogate fuel formulation. J. Eng. Gas Turbines Power, 132(11), 111501 (2010).

[24] Anand K., Ra Y., Reitz R.D., Bunting B.: Surrogate model development for fuels for advanced combustion engines. Energy Fuels, 25(4), 1474-1484 (2011).

[25] Schulz W.D.: Oxidation products of a surrogate JP-8 fuel. Preprints-American Chemical Society. Division of Petroleum Chemistry, 37(2), 383-392 (1992).

[26] Delfau J.L., Bouhria M., Reuillon M., Sanogo O., Akrich R., Vovelle C.: Experimental and computational investigation of the structure of a sooting decane-O2-Ar flame. Proc. Combust. Inst., 23, 1567-1572 (1991). 
[27] Cathonnet M., Balès-Guéret C., Chakir A., Dagaut P., Boettner J.C., Schultz J.L.: On the use of detailed chemical kinetics to model aeronautical combustors performances. Proc. of the third European propulsion forum, EPF91, ONERA Paris, AAAF (1992).

[28] Dagaut P.: On the kinetics of hydrocarbons oxidation from natural gas to kerosene and diesel fuel. Phys. Chem. Chem. Phys., 4(11), 2079-2094 (2002).

[29] Luche J., Reuillon M., Boettner J.C., Cathonnet M.: Reduction of large detailed kinetic mechanisms: application to kerosene/air combustion. Combust. Sci. Technol., 176(11), 19351963 (2004).

[30] Franzelli B., Riber E., Sanjosé M., Poinsot T.: A two-step chemical scheme for kerosene-air premixed flames. Combust. Flame, 157(7), 1364-1373 (2010).

[31] Bénard P., Moureau V., Lartigue J., D'Angelo Y.: Large-Eddy Simulation of a hydrogen enriched methane/air meso-scale combustor. Int. J. Hydrog. Energy, 42(4), 2397-2410 (2017).

[32] Boussinesq J.: Théorie de l'écoulement tourbillonant. Mem. Pres. Acad. Sci., 23-46 (1877).

[33] Germano M., Piomelli U., Moin P., Cabot. W.H.: A dynamic subgrid-scale eddy viscosity model. Phys. Fluids A : Fluid Dynamics (1989-1993), 3(7), 1760-1765 (1991).

[34] Butler T.D., O'Rourke P.J.: A numerical method for two dimensional unsteady reacting flows. Proc. Combust. Inst., 16, 1503-1515 (1977).

[35] Légier J.P., Poinsot T., Veynante D.: Dynamically thickened flame les model for premixed and nonpremixed turbulent combustion. Proc. of the summer program, 157-168 (2000).

[36] Charlette F., Meneveau C., Veynante D.: A power-law flame wrinkling model for LES of premixed turbulent combustion Part I: non-dynamic formulation and initial tests, Combust. Flame, 131(1-2), 159-180 (2002).

[37] Guédot L.: Développement de méthodes numériques pour la caractérisation des grandes structures tourbillonnaires dans les brûleurs aéronautiques : application aux systèmes d'injection multi-points. PhD thesis at Institut National des Sciences Appliquées de Rouen, FRANCE (2015).

[38] Schiller L., Naumann Z.: A drag coefficient correlation. Vdi Zeitung, 77(318), 51 (1935).

[39] Spalding D.B.: The combustion of liquid fuels. Proc. Combust. Inst., 4, 847-864 (1953).

[40] Abramzon B., Sirignano W.: Droplet vaporization model for spray combustion calculations. Int. J. Heat Mass Transfer, 32(9), 1605-1618 (1989).

[41] Kuo K.: Principles of combustion. John Wiley \& Sons (1986).

[42] Sirignano W.A.: Fluid dynamics and transport of droplets and sprays. Cambridge University Press (2010).

[43] Guédot L., Lartigue G., Moureau V.: Modeling and Analysis of the Interactions of Coherent Structures with a Spray Flame in a Swirl Burner. Turbul. Interactions, 15-26 (2015).

[44] Farcy B., Vervisch L., Domingo P.: Large eddy simulation of selective non-catalytic reduction (SNCR): A downsizing procedure for simulating nitric-oxide reduction units. Chem. Eng. Sci, 139, 285-303 (2016).

[45] Esclapez L., Ma P.C., Mayhew E., Xu R., Stouffer S., Lee T., Ihme M.: Fuel effects on lean blow-out in a realistic gas turbine combustor. Combust. Flame, 181, 82-99 (2017).

[46] Okong'o N.A., Bellan J.: Consistent large-eddy simulation of a temporal mixing layer laden with evaporating drops. Part 1: direct numerical simulation, formulation and a priori analysis. J. Fluid Mech., 499, 1-47 (2004).

[47] Bini M., Jones W.P: Particle acceleration in turbulent flows: A class of nonlinear stochastic models for intermittency. Phys. Fluids, 19(3) (2007). 
[48] Hannebique G., Sierra P., Riber E., Cuenot B.: Large-eddy simulation of reactive two-phase flow in an aeronautical multipoint burner. Flow Turbul. Combust., 90(2), 449-469 (2013).

[49] Sanjosé M., Senoner J.M., Jaegle F., Cuenot B., Moreau S., Poinsot T.: Fuel injection model for euler-euler and euler-lagrange large-eddy simulations of an evaporating spray inside an aeronautical combustor. Int. J. Multiphase Flow, 37(5), 514-529 (2011).

[50] Fourier J.: Théorie analytique de la chaleur. Chez Firmin Didot, père et fils (1822).

[51] Malandain M., Maheu N., Moureau V.: Optimization of the deflated Conjugate Gradient algorithm for the solving of elliptic equations on massively parallel machines. J. Comput. Phys., 238, 32-47 (2012).

[52] Luo J., Razinsky E.H.: Conjugate heat transfer analysis of a cooled turbine vane using the v2f turbulence model. J. Turbomach., 129(4), 773-781 (2007).

[53] He L., Oldfield M.L.G.: Unsteady conjugate heat transfer modeling. J. Turbomach., 133(3), 031022 (2011).

[54] York W.D., Leylek J.H.: Three-dimensional conjugate heat transfer simulation of an internally-cooled gas turbine vane. ASME Turbo Expo 2003, collocated with the 2003 International Joint Power Generation Conference, GT2003-38551, 351-360 (2003).

[55] Duchaine F., Corpron A., Pons L., Moureau V., Nicoud F., Poinsot T.: Development and assessment of a coupled strategy for conjugate heat transfer with large eddy simulation: application to a cooled turbine blade. Int. J. Heat Fluid Flow., 30(6), 1129-1141 (2009).

[56] Jauré S., Duchaine F., Staffelbach G., Gicquel L.Y.M.: Massively parallel conjugate heat transfer methods relying on large eddy simulation applied to an aeronautical combustor. Comput. Sci. Discov., 6(1), 015008 (2013).

[57] Florenciano J.L., Bruel P.: LES fluid-solid coupled calculations for the assessment of heat transfer coefficient correlations over multi-perforated walls. Aerosp. Sci. Technol., 53, 61-73 (2016).

[58] Scholl S., Verstraete T., Duchaine F., Gicquel L.: Conjugate heat transfer of a rib-roughened internal turbine blade cooling channel using large eddy simulation. Int. J. Heat Fluid Flow., 61, 650-664 (2016).

[59] Misdariis A., Vermorel O., Poinsot T.: LES of knocking in engines using dual heat transfer and two-step reduced schemes. Combust. Flame, 162(11), 4304-4312 (2015).

[60] Giles M.B.: Stability analysis of numerical interface conditions in fluid-structure thermal analysis. Int. J. Numer. Methods Fluids, 25(4), 421-436 (1997).

[61] Felippa C.A., Park K.C., Farhat C.: Partitioned analysis of coupled mechanical systems. Comput. Methods Appl. Mech. Eng., 190(24), 3247-3270 (2001).

[62] Duchaine F., Jauré S., Poitou D., Quémerais E., Staffelbach G., Morel T., Gicquel L.: Analysis of high performance conjugate heat transfer with the OpenPALM coupler. Comput. Sci. Discov., 8(1), 015003 (2015).

[63] http://www.cerfacs.fr/globc/PALM_WEB/.

[64] Shapiro R.: Linear filtering. Math. Comput., 29(132), 1094-1097 (1975).

[65] Maheu N., Moureau V., Domingo P.: Large-eddy simulations of flow and heat transfer around a low-Mach number turbine blade. Proc. of the Summer Program, 137-146 (2012).

[66] Nguyen P.D., Moureau V., Vervisch L., Perret N.: A massively parallel solution strategy for efficient thermal radiation simulation. J. Phys. Conf. Series, 369(1), 012017 (2012). 